\title{
Anisotropy Study of Inconel 718 alloy at Sub-Zero temperatures
}

\author{
Jayahari $\mathrm{L}^{1 *}$, Nagachary $\mathrm{K}^{1}$, Sharath Chandra $\mathrm{Ch}^{1}$, and Hussaini $\mathrm{SM}^{2}$ \\ ${ }^{1}$ Gokaraju Rangaraju Institue of Engineering \& Technology, Hyderabad, India \\ ${ }^{2}$ Vignan Institue of Science \& Technology, Hyderabad, India
}

\begin{abstract}
There is an increase in demand for new alloys in aerospace, power generation and nuclear industries. Nickel Based super alloys are known for having distinctive properties which are best suitable for these industries. In this study Nickel based super alloy Inconel 718, is used. Over the many years of intense research and development, these alloys have seen considerable evolution in their properties and efficiency. Behaviour of materials and its forming characteristics can be precisely analysed by determining anisotropic behaviour and mechanical properties. In the present study, tried to analyse the mechanical properties of Inconel 718 like yield strength $\left(\mathrm{Y}_{\mathrm{s}}\right)$, ultimate tensile strength (UTS), strain hardening exponent $(\mathrm{n})$ and strain hardening coefficient $(\mathrm{k})$. Uni-axial tensile tests were conducted on specimens with various parameters such as orientations, temperature and Strain rate. Anisotropy of Inconel 718 alloy was measured based on measurable parameters. The normal anisotropy parameter $(\bar{r})$ and planer anisotropy $(\Delta \mathrm{r})$ were measured and observed that the anisotropy parametres are incresed with the decrease in temperature.
\end{abstract}

\section{Introduction}

Anisotropic properties and strain hardening behaviour is an important for processing of material and maintaining safety operation during work. Generally, nickel based super alloys are having the good mechanical properties at high temperatures which results in the improving performance of these alloys. Reed Rc et al [1] concluded that the anisotropic properties and work hardening behaviour at high temperatures which ends up within the Safe region and healthy working conditions because material is high strength to lightweight ratio. They are mostly utilizing in the aerospace applications. Gaury et al [2] studied the determination of work hardening behaviour, mechanical properties, anisotropic parameters of Inconel 718 at various working conditions with various temperatures and strain rates at elevated temperatures. Mang Ni et al [3] investigated the anisotropic mechanical properties and the microstructure of selective laser melting processed Inconel718 and found that with decrease in density, decrease with the input Energy requirement. Nickel based super alloys widely utilized in the aerospace applications and wrought types of applications in that observed high growth within the powder technologies of solidification [4]. Khotso Khoele et al [5] studied the corrosion behaviour and mechanical properties of Inconel 718 with graphene nanoplatelets, and also observed the uniform corrosion in inconel718, increase in hardness, less reduction of young's modulus at high temperatures. Inconel 718 could be a nickel chromium base super alloy mostly employed for the aerospace industries and at cryogenic temperatures. Several engine parts are using in extreme conditions and explained that Inconel718 has stretch forming behaviour
[6]. Sandeep et al [7] studied the mechanical properties of copper alloy at sub-zero temperatures in different cross head velocities and different orientations. In this styudy the copper alloy shows properties like ultimate strength and yield strength decrease with increases in temperatures from sub-zero to room temperature and also increases the fracture stresses in this temperature zone. It was also studied that at cryogenic temperatures Inconel having the high ultimate durability.

Hot deformation behaviour of delta-processed Inconel 718 has been investigated, with the microstructure of the alloy before and after the delta processing, before the deformation, and after the deformation tracked and at high temperatures different strain rates are used the predictive approach. This leads to the apparent approach which causes the dynamic recrystallization within the specimens. Strain rates are quasi -statice to the quasi dynamic regions which analysis the model to predict the height stress with good accuracy [8-11]. The high strength materials like Austenitic stainless steels and EDD steel are considered to study the forming behaviour of material at elevated temperatures and at room temperature. Through material characterization and formability test, the mechanical properties are used in LS-DYNA Constitutive models to study the forming behaviour of steels at various temperatures and observed that there is an improvement in formability of steels used for major applications[1215].

Dharavath Baloji et al [16] Studied the effects of orientations, temperatures and velocity on the strain hardening exponent and supreme strength of ASS316L using Taguchi method. By using ANOVA to grasp that temperature is most vital and influencing parameter. A

\footnotetext{
* Corresponding author: 1.jayahari@griet.ac.in
} 
scientific approach and therefore the work investigated the anisotropic yield criteria and model by using finite element analysis of Inconel 625 alloy and also determine the mechanical properties at the elevated temperatures with an interval of $100^{\circ} \mathrm{C}$ with conducting uniaxial tensile tests. From the info, the anisotropic yield behavior determined by using the Barlat parameter of Inconel 625 alloy is nice accuracy [17]. The results of the anisotropy covers the dislocation, thickness and therefore the composition of the Inconel 600 alloy and also surface properties are interlinked with the orientation of crystallographic structure which helps within the healthy working conditions of the Inconel alloy and also done deep study regarding the anisotropic surface properties and also increases the rate of corrosion [18]. Dunyong et al [19] studied the material characterization the anisotropic mechanical properties and microstructure of the Inconel 718 at different conditions and their fractography study confirms the surface with ductile dimple fracture feature in all the directions of the Inconel 718. The phenomenon occurs in Inconel 625 solution strengthen super alloy and investigated the mechanical properties and conducted the tensile experiments at elevated temperatures with various strain rates and also find interactions and dislocations within the Inconel 625 with tensile and compression test at high deformation speeds. Work hardening behavior of the nickel-based alloys helps to increase strength within the hot forming processes. During the study dispensed the new compression tests with variation in strain rate and different temperatures and described the work hardening behavior rate. Decreases the rate of deformation with the decrease in strain rate and increases with the temperature of the nickel based super alloys [20].

\section{Material and Experimental}

\subsection{Material and specimen}

Inconel 718 is an alloy from the Nickel family of super alloys. For particular applications like turbine blades, it is one of the foremost commonly used materials for higher temperature applications in the industries. Among the latter, they're often utilized in environments where the conditions for the environment are extreme. During this study tensile specimens are made by using wire cut EDM. The samples are cut in the different orientations in the rolling, normal and transverse directions as per the standards. The chemical composition of the Inconel718 alloy as shown in the Table 1 .

Table 1. Chemical composition of Inconel 718 alloy

\begin{tabular}{|c|c|c|c|c|c|c|}
\hline Element & $\mathrm{Ni}$ & $\mathrm{Cr}$ & $\mathrm{Nb}$ & $\mathrm{Mo}$ & $\mathrm{Fe}$ & Other \\
\hline Wt. $\%$ & 50.63 & 18.966 & 4.786 & 3.214 & 19.80 & Rest \\
\hline
\end{tabular}

\subsection{Tensile Experimentation}

The experiments were conducted on Universal Testing Machine (UTM) at the sub-zero temperatures. The temperatures were $-5^{\circ} \mathrm{C},-10^{\circ} \mathrm{C},-20^{\circ} \mathrm{C},-25^{\circ} \mathrm{C},-35^{\circ} \mathrm{C}$, - $40^{\circ} \mathrm{C},-50^{\circ} \mathrm{C},-55^{\circ} \mathrm{C},-65^{\circ} \mathrm{C}$. Uniaxial tensile testing performed at constant strain rate $0.01 / \mathrm{s}$ and at different orientations and calculated the properties. The Universal testing machine is as shown in the figure. And the specimens are marked with $5 \mathrm{~mm}$ intervals of the $30 \mathrm{~mm}$ gauge length of the specimen and width $6.4 \mathrm{~mm}$ and thickness $1 \mathrm{~mm}$.

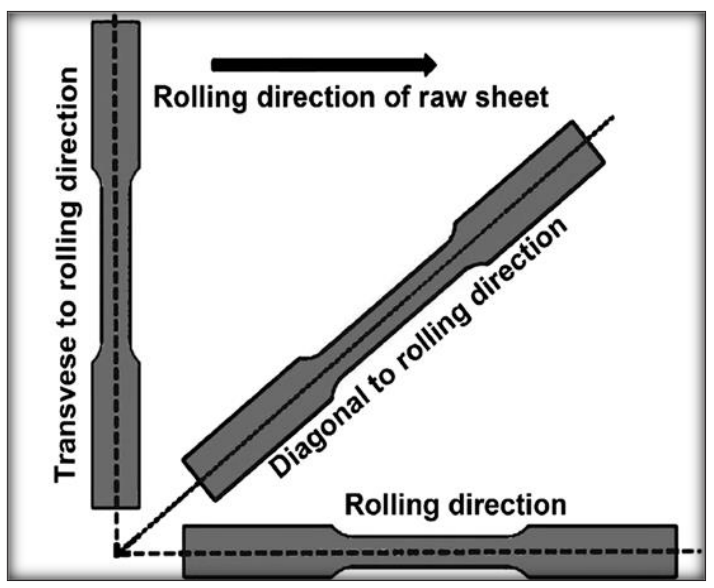

Fig 1: a) Specimens in three directions

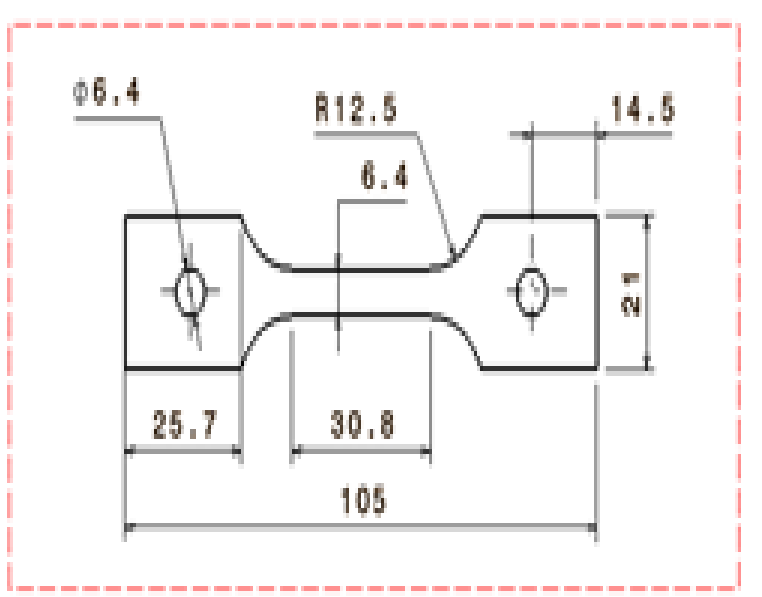

Fig 1:b) Tensile Specimen Dimension as per standard

The total experiment setup is as shown in the figure 2, in this tensile test were conducted on the computerized Universal Testing Machine and also view the magnifying view of the specimen placed between the two holding rods and pins in the chamber of the UTM machine.

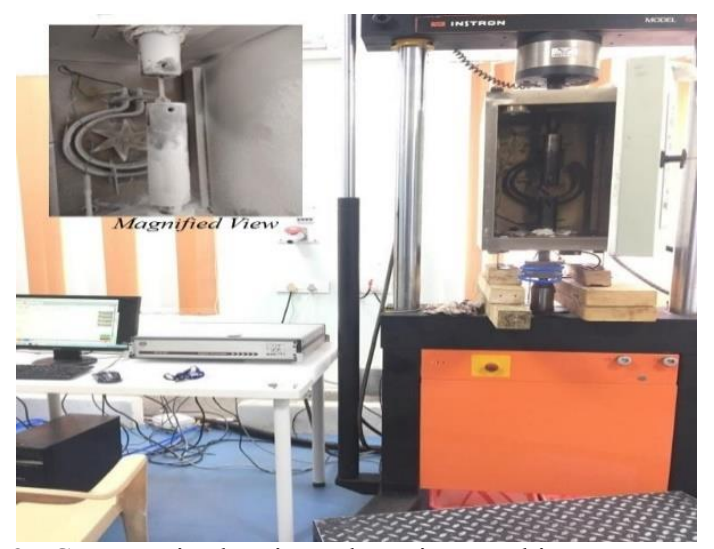

Fig 2 : Computerized Universal Testing Machine 
The tensile experiments were performed at steady $0.01 / \mathrm{sec}$ strain rate and varying temperature ranging from the subzero temperatures up to $-65^{\circ} \mathrm{C}$ temperature with an interval of $5^{\circ} \mathrm{C}$ temperature in three different direction of the material along with the rolling direction which are conducted on the universal testing machine. First drawn lines on the specimen's along gauge length at an interval of $5 \mathrm{~mm}$, and next the specimen is placed between the two rods which are connected with the help of pins made from wrought Inconel. Closed the chamber and start the passage of $\mathrm{CO}_{2}$ gas at $-70^{\circ} \mathrm{C}$ for cool the chamber, once reached the required temperature stops the gas and material is soaked from 5 to 10 min time. After that, start the test by gradually applying force on the specimen which results in the starting the elongation of the material, as the force increases with the steady strain rate then the elongation of the specimen continued. The specimen is separated after incremental elongation until the stress exceeds the highest tensile strength. At a certain point it will break, that point is called as then breaking point and at which amount of strength beared is called as the ultimate tensile strength of the specimen. The following figures 3(a) shows the specimen before testing and figure(b)after experimentation which results elongation in the middle of the gauge length of the specimen.

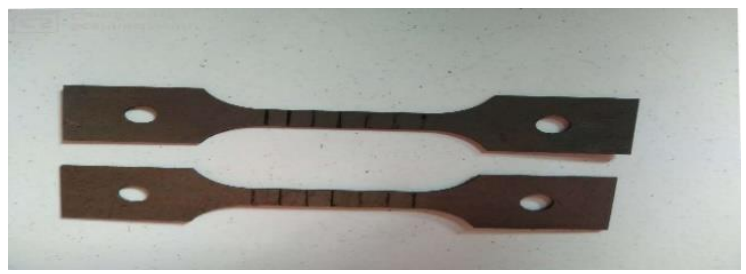

Fig 3: a) Marked Tensile Test specimen

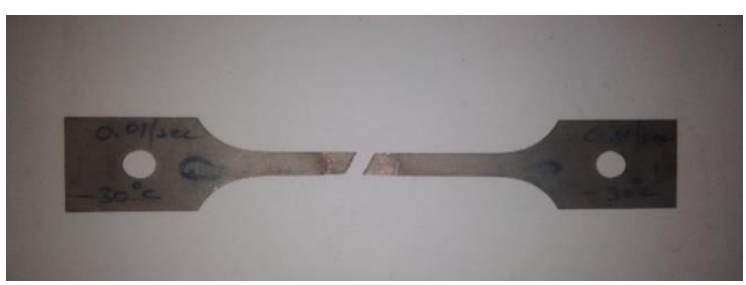

Fig 3 b) Broken Tensile test piece

\section{Result and discussions}

Force and displacement data got from the UTM, from this data, found the tensile properties of materials. Tabulated the mechanical properties in the table 2; are yield stress, young's modulus, \% elongation, strain hardening exponent and the strength coefficient of the material at various temperatures.

Table 2: Mechanical Properties of Inconel718 at various temperatures

\begin{tabular}{|c|c|c|c|c|c|c|c|}
\hline $\begin{array}{l}\text { n } \\
\text { o }\end{array}$ & $\begin{array}{c}\text { Tem } \\
\text { perat } \\
\text { ure } \\
\left({ }^{0} \mathrm{c}\right)\end{array}$ & $\begin{array}{c}\text { Max } \\
\text { Stre } \\
\text { ss } \\
\text { (Mp } \\
\text { a) }\end{array}$ & $\begin{array}{c}\text { Yiel } \\
\text { d } \\
\text { Stre } \\
\text { ss } \\
\text { (Mp } \\
\text { a) }\end{array}$ & $\begin{array}{c}\text { Young' } \\
\text { s } \\
\text { Modul } \\
\text { us } \\
\text { (Gpa) }\end{array}$ & $\begin{array}{c}\text { Elong } \\
\text { ation } \\
(\%)\end{array}$ & $\begin{array}{c}\text { Strain } \\
\text { Harde } \\
\text { ning } \\
\text { expone } \\
\text { nt } \\
\text { (n) }\end{array}$ & $\begin{array}{c}\text { Stre } \\
\text { ngth } \\
\text { Co- } \\
\text { Eff } \\
\text { (K) }\end{array}$ \\
\hline
\end{tabular}

\begin{tabular}{|c|c|c|c|c|c|c|c|}
\hline 1 & -5 & 744. & 345. & 12.02 & 69.21 & 0.4562 & 180. \\
& & 9 & 3 & & 3 & & 85 \\
\hline 2 & -10 & 811. & 429. & 13.368 & 69.17 & 0.348 & 277. \\
& 3 & 11 & & 2 & & 3 \\
\hline 3 & -20 & 807. & 428. & 9.267 & 78.69 & 0.4613 & 176. \\
& & 5 & 527 & & 5 & & 46 \\
\hline 4 & -25 & 808. & 447. & 8.966 & 74.74 & 0.3179 & 278. \\
& & 6 & 52 & & & & 43 \\
\hline 5 & -35 & 754. & 394. & 7.256 & 68.22 & 0.4556 & 178. \\
& & 6 & 18 & & 4 & & 66 \\
\hline 6 & -40 & 838. & 438. & 11.49 & 77.92 & 0.2626 & 340. \\
& & 7 & 28 & & 3 & & 35 \\
\hline 7 & -50 & 826. & 455. & 10.22 & 80.16 & 0.3075 & 240. \\
& & 6 & 68 & & & & 97 \\
\hline 8 & -55 & 846. & 490. & 10.47 & 74.52 & 0.3958 & 241 \\
& & 6 & 68 & & & & \\
\hline 9 & $-65^{\circ} \mathrm{C}$ & 849. & 445. & 13.52 & 71.16 & 0.5023 & 187. \\
. & & 20 & 07 & & & & 81 \\
\hline
\end{tabular}

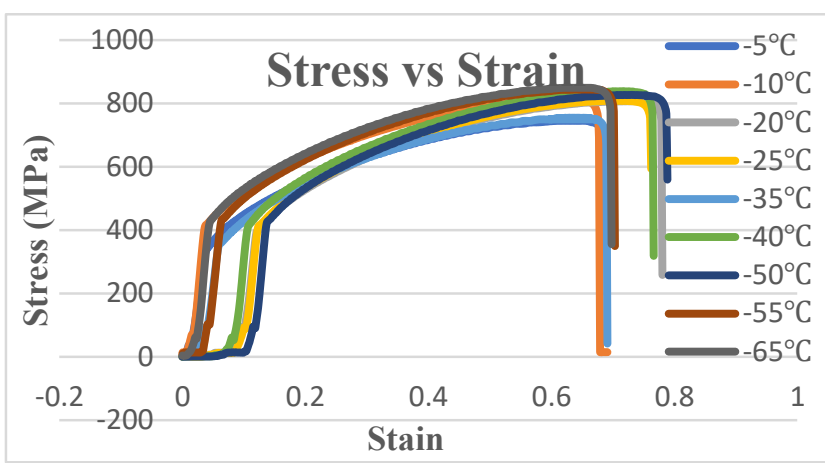

Fig 4: Stress Vs Strain Diagrams at Sub Zero temperatures

Figure 4: drawn between the stress and strain of the tested specimens, it is observed that at a lower temperature, materials have high strength. It is found that the quality of the substance becomes more influenced by temperature decrease. Strength of the Inconel 718 increases with the decreases in temperature due to the reduction in flow stress. Decrease in temperature also effects ductility of the material there by increasing in the brittleness and decreases the ductility and also observed that the mechanical properties of the Inconel718 are most effect with the variation of the temperature.

From the data of the results, the strain hardening exponent (n) and the strength coefficient $(\mathrm{k})$ calculating with a relation plot between the $\ln$ (true stress) and $\ln$ (true strain) and applying the trend line to the curve in linear condition which gives an equation in the form of $y=$ $\mathrm{mx}+\mathrm{c}$. In that $\mathrm{m}$ value is equal to the Strain hardening exponent (n) and the exponent of the $\mathrm{C}$ value is the strength coefficient (k). In Figure 5 shows Ultimate Tensile Strength Vs Temperature graph, which show increase in ultimate tensile strength with the decrease in temperature ranging from the sub-zero to the $-65^{\circ} \mathrm{C}$ in all three orientations of the specimens at constant strain rate $0.01 / \mathrm{sec}$ 


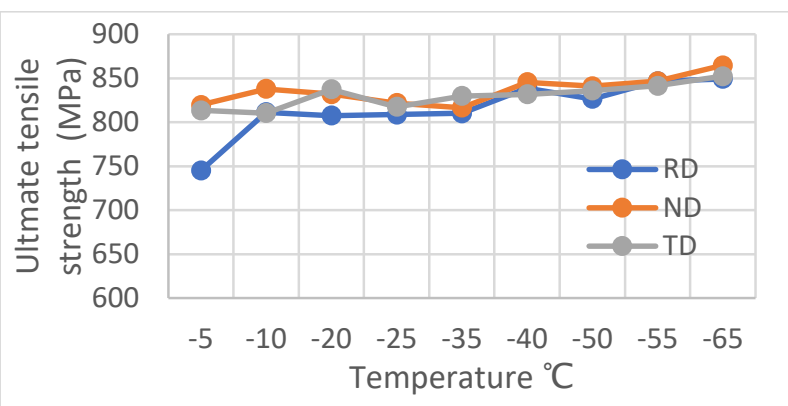

Fig 5: Ultimate Tensile Strength Vs Temperature

Table 3: Inconel718 Tensile test Anisotropy result

\begin{tabular}{|c|c|c|c|}
\hline S.no & Temperature & $\begin{array}{c}\text { Normal } \\
\text { anisotropy } \\
\text { parameter } \\
\left(\mathbf{r}^{-}\right)\end{array}$ & $\begin{array}{c}\text { Planer } \\
\text { anisotropy } \\
\text { parameter } \\
(\mathbf{\Delta r})\end{array}$ \\
\hline 1 & $-5^{\circ} \mathrm{C}$ & 0.8428 & -0.3869 \\
\hline 2 & $-10^{\circ} \mathrm{C}$ & 0.8754 & -0.1286 \\
\hline 3 & $-20^{\circ} \mathrm{C}$ & 0.8084 & -0.0224 \\
\hline 4 & $-25^{\circ} \mathrm{C}$ & 0.8940 & -0.1304 \\
\hline 5 & $-35^{\circ} \mathrm{C}$ & 0.8601 & -0.1891 \\
\hline 6 & $-40^{\circ} \mathrm{C}$ & 0.8976 & -0.1521 \\
\hline 7 & $-50^{\circ} \mathrm{C}$ & 0.7839 & -0.1660 \\
\hline 8 & $-55^{\circ} \mathrm{C}$ & 0.8492 & -0.1849 \\
\hline 9 & $-65^{\circ} \mathrm{C}$ & 0.8475 & -0.2292 \\
\hline
\end{tabular}

The anisotropic values are evaluated from the experimentally as note down the initial gauge length (Li) and initial gauge width (Wi) of the specimen which marked as length with an interval of the $5 \mathrm{~mm}$ from the center of the gauge length and width of the specimen before starting the experiment. Next, after the experimentation measured the length and width of the broken tensile samples as final gauge length $\left(\mathrm{L}_{\mathrm{f}}\right)$ and final gauge width $\left(\mathrm{W}_{\mathrm{f}}\right)$, which previously marked intervals with the help of digital Vernier calipers. It is very difficult to measure precision at a particular point that's why taking the averages of the intervals generally, after experimentation gauge length of the specimen increases and the width of the specimen decreases due to necking phenomenon occurs before braking of the specimen.

Applying $\ln$ to the final measurement to initial measurement of the specimen evaluated the $\left(\varepsilon_{\mathrm{L}}\right)$ and $\left(\varepsilon_{\mathrm{W}}\right)$, to next determined the Normal anisotropy parameter ' $\bar{r}$ ', value for the three orientations of the specimens as $\mathrm{r} 0, \mathrm{r} 45$, r90 generally $\mathrm{r}$ - value in sheet metal using for the deep drawing applications. then next evaluated the Planer anisotropy parameter $\Delta \mathrm{r}$.

$$
r=\varepsilon W /-(\varepsilon W+\varepsilon L)
$$

$$
\begin{gathered}
\mathrm{r}^{-}=(\mathrm{r} 0+2 \mathrm{r} 45+\mathrm{r} 90) / 4 \text { and } \\
\Delta \mathrm{r}=(\mathrm{r} 0-2 \mathrm{r} 45+\mathrm{r} 90) / 2
\end{gathered}
$$

Where

$\mathrm{r}=$ plastic strain ratio

$(\bar{r})=$ Normal Planer anisotropy parameter and

$(\Delta \mathrm{r})=$ Planer anisotropy parameter

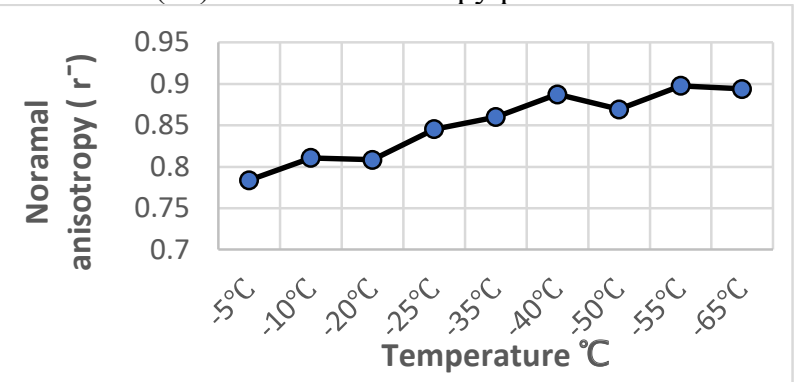

Fig 6 (a): Normal anisotropy vs Temperature

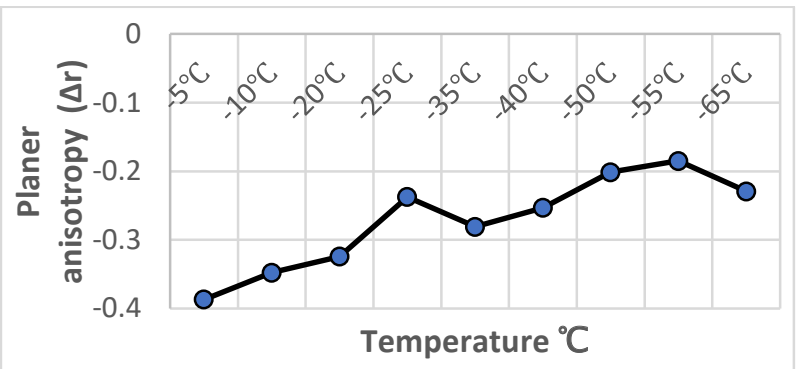

Fig 6 (b): Planer anisotropy vs Temperature

From the above Figure 6, Anisotropy vs Temperature graphs, Normal anisotropy parameter $(\bar{r})$ and Planer anisotropy parameter $(\Delta \mathrm{r})$ changes with the variation of temperature. As the result of the experimental calculations the anisotropy values are decreases with decrease of temperature from sub-zero to $-65^{\circ} \mathrm{C}$. The Normal anisotropy parameter value slightly increase with in the decrease in temperature and the Planer anisotropy parameter also increases in negative with decrease of the temperature normally

\section{Conclusions}

This work focuses on the characterization, anisotropic parameters and mechanical behavior of Inconel 718 at sub-zero temperature and strain rate $0.01 / \mathrm{sec}$ have the following conclusions.

$>$ The yield strength and ultimate tensile strength of the inconel718 increases with the decrease in temperature.

$>$ Temperature effects on the mechanical properties of then Inconel718 when exposed to the varying temperatures exhibited the decrease in the ductility with dropped in the temperature.

$>$ The Normal anisotropy parameter $(\bar{r})$ and Planer anisotropy parameter $(\Delta \mathrm{r})$ are slightly increases within the decrease in temperature of the specimen in plastic region. 


\section{Acknowledgment}

The authors would like to thank JNTU-Hyderabad for financial support of this research work (through TEQIP-III) JNTUH/TEQIP-III/CRC/2019/MECH/03.

\section{References}

1. R.C. Reed, New York, Cambridge University 2006

2. Gauri Mahallea, Nitin Kotkundea, Amit Kumar Guptaa, Swadesh Kumar Singh. J.Mat. Res.Tech, 8, 2130-2140(2019)

3. Mang nia, Chao Chena, Kechao Zhoua, 344351(2017)

4. R. Patterson, A.Cox, J.Met. Sci 32, 34-39(1980)

5. Khotso Khoele. David Jacobus Delport, J.Failure Analy \&Prev 19, 1493-1497(2019)

6. K.Sajun Prasad, T. Kamal, S.K. Panda, S. Kar, S.V.S. Narayana Murty and S.C Sharma ; Mat. Today : Proc 22037 - 2045(2015)

7. M Sandeep, L Jayahari, K Satyanarayana, M Dinesh, V Vinod Kumar. Mat. Today: Proc, 18, 4458-4465 (2019)

8. Jia-Bao Yan, Jian Xie, Construction and Building Materials 151 661-67(2017)

9. Hussaini, S.M., Singh, S.K. and Gupta, A.K., J. Mat Res \& Tech, 3(1), 17-24(2014)
10. M.Azarbarmas, M. Aghaie khafri, M. Cabrera, J.Calvo, 94, 28-38(2016)

11. Jayahari, L., Sasidhar, P.V., Reddy, P.P., BaluNaik, B., Gupta, A.K. and Singh, S.K. J.King Saud UniEngg Sci, 26, 21-31(2014)

12. Christopher A.Schuh, Kelly Anderson b, Christine orme. J\&B, Sur.Sci, 544, 183-192(2003)

13. Singh, S.K., Gupta, A.K. and Mahesh, K., 3(1),73-79 (2010)

14. Prasad, K.S., Gupta, A.K., Singh, Y. and Singh, S.K., J.Mat.Engg \& Per, 25(12), 5411-5423(2016)

15. Jayahari L, Balu Naik B, Gupta AK,S.K.Singh . J.Iron\& Steel Int. 21(12):1147-1151(2014)

16. Dharavath Baloji, Kalluri Anil, K Satyanarayana, Ahsan ul haq, Swadesh Kumar Singhb, M.T.Naik. Mat. Today: Proc18 4475-4481(2019)

17. Nitin Kotkunde, Anand Basrish, Ayush Morchhale, Swadesh kumar singh, Mat. Today: Proc18 27602766(2019)

18. Bankupalli, P.T., Srikanth Babu, V., Suresh Kumar. $\mathrm{T}$, International Journal of Applied Engineering Research, 10(16), 2015

19. Dunyong denga, Johan Moverarea, Ru lin Penga, Mat. Sci.Engg, 151-163(2017)

20. P.Maj, J.Zdunek, J.Mizera, B.Sakowicz. Met \& Mat intl, 23, 54-67(2017) 